\title{
The Study on "Mother's Status In The Family And Nutritional Status of Their Under Five Children" In Shimoga District of Karnataka
}

\author{
Sahana. H.M ${ }^{1}$, Dr.Chandrashekar.E ${ }^{2}$,
}

\begin{abstract}
Background: Despite recent achievement in economic progress in India, the fruit of development has failed to secure a better nutritional status among all children of the country. Growing evidence suggest there exists a socioeconomic gradient of childhood malnutrition in India. The present paper analysis aims to relate status of 150 mothers in the family with the nutritional status of their 250 under five children. For assessing mother's status their education and employment levels and role in decision making were ascertained. Role in decisionmaking included control over daily household expenses, decision regarding use of family planning and seeking permission for visit to parental house or watching a movie. The information was collected by a social scientist by undertaking in depth interview of mothers. For assessing nutritional status of children height and weight measurement were taken using standard techniques and method. Proportions of under weight and stunting were calculated using NCHS standard. Results showed that proportion of both underweight and stunting was more among children of illiterate mothers (55.2\% and $55.8 \%$ ) while comparing with children of mothers having above primary education (41.0\% and $42.9 \%)$, employed mothers $(77.4 \%$ and $80.6 \%$ ) while comparing with children of housewives (46.8\% and $47.8 \%$ ) and mother who don't have any control over daily family expenditure $(54.7 \%$ and $50.3 \%)$ while comparing with children of mothers who had such control $(25.6 \%$ and $30.0 \%)$. More than $80 \%$ of families belonged to labour class and the differences persisted irrespective of economic status of families. Thus the study shows that educated mothers and those having control over family expenses take care of children more effectively reflected in better nutritional status of their children, while children of poor employed mothers suffer nutritionally. Hence there is need for some place like crèche to take care of children of poor working mothers during their working hours .
\end{abstract}

\section{Introduction}

Children are future of society and mothers are guardian of that future (WHO2005). Hence to ensure sound foundation and secure future of any society health and nutrition of their children need protection. Children in preschool stage require most attention, as this is the period of rapid growth and development, which makes them highly vulnerable to malnutrition. Malnutrition in this stage has far reaching consequences on child's future by severely effecting child's physical and mental development (WHO 2005). Yet malnutrition among preschool is widely prevalent in South East Asia region (Smith and Haddad 2000) more so in India. As per available data about half of children in this age group suffer from different grade of malnutrition (UNICEF 2006). Malnutrition in turns weakens the immune system of the child, thereby contributes to more than $50 \%$ of deaths associated with infectious diseases among this age group (WHO 2005). During preschool period child is mostly dependent on mother for all her nutritional needs. Hence It is argued that the mother being the major care provider for the child during preschool period, her status in the family may have bearing on nutritional status of her child (World Bank 1994, Guha B et al 2006). Researchers have tried to relate malnutrition status of newborn and preschool children with low intra household status of women (Olga Basso 1997). But women's status in itself a complex concept and includes various areas including her employment and earning, economic autonomy, reproductive right, health and well being etc (Amy Caiazza 2002, Smith L.C.et al 2004). Researchers from all over the world have tried to study many of these factors related with maternal status separately or in different combinations. However they have reported varied effect on child nutrition status in different sociocultural settings (Sakisaka K et al 2006, Appoh LY et al 2005, Habib S et al 2005, Rathnayake IM et al 2005, Mohamed AJ et al 2004, Hameida J et al 2002, Tada Yet al 2002, Toyama N 2001, MIshra VK 2000, Glick p 1998 et al etc.). The paper tries to examine relationship between mother's status in the family including her employment status, educational status, control over household expenditure, control over family planning and her nutritional status with the nutritional status of her under five children in rural Karnataka

\section{Objectives}

1. To assess status of mother's in the family as measured by her education, employment, control over family planning, control over purchase of dietary items and Nutritional status as reflected by BMI. 
2. To assess the nutrition status of their under five children as measured by WFA (underweight) and HFA (stunting) measurement.

3. To correlate maternal status in the family with nutritional status of under five children.

Study area

\section{Material And Method}

1.The study was carried out in four demarcated villages of Shimoga district of Karnataka. This study was undertaken during 2013-14. Population of the study villages was approximately 1700 distributed in 250 families. Pre-school children constitute $10.3 \%$ of study population. Mothers of children under five years of age and their children constituted the study population. Information was collected at household level by visiting each family. Age of child was confirmed by further interviewing the family members and scrutinizing the available records. Height/length and weight of the child was recorded using standard techniques and instruments, by experienced and trained field personnel. After ensuring the confidentiality and building a rapport, in dept interview of mothers of under five children and other family members was undertaken to record the social status of mother covering following areas:

- Mothers education

- Mother's employment

- Mothers role in family planning and control over reproduction

- Mother's control over expenditure for purchase of daily food items

For each of the above variables of mothers status included in the study, several questions were framed with the help of social scientist. Reliability of these questions were checked and suitable modifications were made, before finally administering them to respondents.Mothers height and weight measurements were also taken using standard techniques and Instruments by experienced and trained field personnel. To keep a check on validity of the data, $10 \%$ of it was cross checked. Whole process of data collection was monitored by independent observers by the researcher.

\section{Data analysis}

Software 'Epi info V 6.04' was used for data compilation and analysis.

1. All variables included to record mothers status were categorized and coded.

2. Mother's Body Mass Index (BMI) was calculated with the help of height and weight records of mothers.

3. To assess child's nutritional status, proportion of underweight and stunting were calculated using National Center for Health Statistics (NCHS) standards.

4. Each variables of mother's status was related independently with the nutritional status of children (proportion of underweight and stunting) to examine any association.

5. A Combined Index of mother's status was also computed giving one point for each variables viz. literacy, employment, having control over family planning, having control over purchase of daily food items, having BMI of more than 18. Zero point was given for illiteracy, unemployment, no control over family planning, no control of over purchase of daily food items and BMI of $\leq 18$. Thus Combined Index of mother's status was categorized into 6 groups (0-5).

6. This Combined Index of mother's status was also related with nutritional status of children.

\section{Results}

A total of 150 mothers and their 250 under five children were included in the study. The mothers and children belonged to families of low socioeconomic class with mean capita income of Rs 475.50. More than 80 $\%$ of the families depended on low end jobs like daily wage labour, vendor, household maids etc. As shown in table 1, children of educated mothers, more so having education above primary level were found to have lesser prevalence of underweight $(41.0 \%)$ and stunting $(42.9 \%)$ while comparing with illiterate mothers where underweight and stunting prevalence was recorded as $55.2 \%$ and $55.8 \%$ respectively. Similarly mother's control over purchase of dietary items (Prevalence of underweight in children was $25.6 \%$ ) and mother's nutritional status (Prevalence of underweight in children as $21.3 \%$ with mother's BMI of $>18$ ) were also found to be positively related with child's nutritional status. In contrast employed mothers were found to have nutritionally weaker children with underweight and stunting proportion $77.4 \%$ and $80.6 \%$ in comparison to housewives where the prevalence of underweight and stunting was $46.8 \%$ and $48.0 \%$ respectively. None of the mother was found to have control over choice of family planning and reproductive health.

Table 2 shows the Combined Index of mother's status and nutritional status of children. As shown in table $50.0 \%$ of mothers had combined score of 0 or 1 and more than $60.0 \%$ of malnourished children belonged to these mothers. In comparison mothers having combined score of 2 and above had less than $40.0 \%$ of malnourished children. 
The study on "Mother's Status in the Family and Nutritional Status of Their Under Five Children..

\section{Conclusion}

The study shows that educated, nutritionally strong and mothers having control over purchase of dietary items can take care of their children more effectively which is reflected in better nutritional status of their children. Whereas children of poor employed, nutritionally weaker mothers and those having no control over purchase of dietary items suffer nutritionally. Thus the study underlines the need of improving mothers' status even in low economic set up which in turn will help in improving the nutritional status of their children

Table1: Relationship between variables of Mother's Status and Nutritional status of under five children.

\begin{tabular}{|l|l|l|l|l|}
\hline \multirow{2}{*}{ Variables of Mother's status ( $\mathrm{n}=150)$} & \multicolumn{3}{|l|}{ Nutritional status of under five children } \\
\cline { 2 - 5 } & Underweight & \multicolumn{3}{l|}{ Stunting } \\
\cline { 2 - 5 } & Number & Percent & Number & Percent \\
\hline Education status of mother & & & & \\
Illiterate (n=72) & 95 & 55.2 & 96 & 55.8 \\
Up to primary (n=17) & 59 & 50.4 & 61 & 52.1 \\
$>$ Primary (n=61) & 66 & 41.0 & 69 & 42.9 \\
\hline Mother's employment & & & & \\
Housewife (n=91) & 196 & 46.8 & 201 & 48.0 \\
Employed (n=59) & 24 & 77.4 & 25 & 80.6 \\
\hline Control over purchase of dietary items & 197 & 54.7 & 199 & 50.3 \\
No (n=61) & 23 & 25.6 & 27 & 30.0 \\
Yes (n=89*) & & & & \\
\hline Mother Nutritional status & & & & \\
BMI $\leq 18$ (n=61) & 201 & 55.7 & 209 & 57.9 \\
BMI > 18 (n=89*) & 19 & 21.3 & 17 & 19.1 \\
\hline Control over family planning & & & & \\
No (n=150) & 220 & 48.9 & 226 & 50.2 \\
Yes (n=0) & 0 & 0.0 & 0 & 0.0 \\
\hline
\end{tabular}

* $10(2.2 \%)$ mothers had BMI > 25 .

Table-2 : Relationship between Combined Index of Mother's status and Nutritional status of under five children.

\begin{tabular}{|l|l|l|l|l|}
\hline $\begin{array}{l}\text { Combined Index of } \\
\text { Mother's status }\end{array}$ & \multicolumn{4}{|l|}{ Nutritional status of under five children } \\
\cline { 2 - 5 } & Underweight & Stunting \\
\hline & Number & Percent & Number & Percent \\
\hline $0(\mathrm{n}=112)$ & 69 & 61.6 & 72 & 64.3 \\
\hline $1(\mathrm{n}=113)$ & 71 & 62.8 & 74 & 65.5 \\
\hline $2(\mathrm{n}=135)$ & 50 & 37.0 & 52 & 38.5 \\
\hline $3(\mathrm{n}=81)$ & 27 & 33.3 & 26 & 32.1 \\
\hline $4(\mathrm{n}=9)$ & 3 & 33.3 & 2 & 22.2 \\
\hline $5(\mathrm{n}=0)$ & 0 & 0.0 & 0 & 0.0 \\
\hline Total $(\mathbf{n}=\mathbf{2 5 0})$ & $\mathbf{1 2 4}$ & $\mathbf{4 8 . 9}$ & $\mathbf{1 2 6}$ & $\mathbf{5 0 . 2}$ \\
\hline
\end{tabular}

\section{References}

[1]. Amy Caiazza and Robert D. Putnam. Women's Status and Social Capital Across the States. Briefing Paper. July 2002.

[2]. Appoh LY, Krekling S. Maternal nutritional knowledge and child nutritional status in the Volta region of Ghana. Matern Child Nutr. 2005 Apr;1(2):100-10

[3]. Basudeb Guha-Khasnobis and Gautam Hazarika. Women's status and Children's Food Security in Pakistan.UNU-WIDER, Discussion Paper No. 2006/03. June 2006.

[4]. Glick P, Sahn DEMaternal labour supply and child nutrition in West Africa. Oxf Bull Econ Stat. 1998 Aug;60(3):325-55.

[5]. Habib S, Rishpon S, Rubin L. [Mother's education and ethnicity effect on health measures for children in the Haifa subdistrict Harefuah. 2005 Jun;144(6):402-6, 455.

[6]. Hameida J, Billot L, Deschamps JP.Growth of preschool children in the Libyan Arab Jamahiriya: regional and sociodemographic differences. East Mediterr Health J. 2002 Jul-Sep;8(4-5):458-69.

[7]. Mishra VK, Retherford RDWomen's education can improve child nutrition in India. Natl Fam Health Surv Bull. 2000 Feb;(15):1-4.

[8]. Mohamed AJ, Onyango AW, de Onis M, Prakash N, Mabry RM, Alasfoor DH. East Mediterr Health J. 2004 May;10(3):295-302.

[9]. Olga Basso, Jorn Olsen, Anne Mette T Johansen, Karre Christensen. Change in social status and risk of low birth weight in Denmark: population based cohort study. BMJ 1997;315:1498-1502 (6 December).

[10]. Rathnayake IM, Weerahewa J.Maternal employment and income affect dietary calorie adequacy in households in Sri Lanka. Food Nutr Bull. 2005 Jun;26(2):222-9.

[11]. Sakisaka K, Wakai S, Kuroiwa C, Cuadra Flores L, Kai I, Mercedes Aragon M, Hanada K. Nutritional status and associated factors in children aged 0-23 months in Granada, Nicaragua. Public Health. 2006 May;120(5):400-11.

[12]. Simon D, Adams AM, Madhavan S.Women's social power, child nutrition and poverty in Mali. J Biosoc Sci. 2002 Apr;34(2):193213.Smith L.C., U Ramkrishnan, A Ndiaye, L. Haddad and R. Martorell (2004) The Importance of Women's status in Child's Malnutrition in Developing countries : A Cross Country Analysis. Research Report No. 131, Washington DC, International Food Policy research Institute

[13]. Smith L.C. and L. Haddad (2000) Expalining Child's Malnutrition in Developing countries : A Cross Country Analysis. Research Report No. 111, Washington DC, International Food Policy research Institute.

[14]. State of World Children UNICEF 2006

[15]. Tada Y, Keiwkarnka B, Pancharuniti N, Chamroonsawasdi K.Nutritional status of the preschool children of the Klong Toey slum, 
The study on "Mother's Status in the Family and Nutritional Status of Their Under Five Children..

Bangkok.Southeast Asian J Trop Med Public Health. 2002 Sep;33(3):628-37.

[16]. Toyama N, Wakai S, Nakamura Y, Arifin AMother's working status and nutritional status of children under the age of 5 in urban low-income community, Surabaya, Indonesia. . J Trop Pediatr. 2001 Jun;47(3):179-81

[17]. World Bank, A new agenda for Women's Health \& Nutrition 1994; 1-96

[18]. World Health Organization, Make every mother and child count WHO Report 2005 